\title{
Awareness of Young Japanese Women on HPV Self- Sampling Trial using Opt-in Method
}

\section{Sayako Tada}

Former Graduate School of Health Sciences, Hokkaido University

Yumi Ito ( $\nabla$ yuyumiito@gmail.com )

Kushiro Rosai Byoin

\section{Natumi Nagai}

Graduate School of Health Sciences, Hokkaido University

\section{Kanako Nakamura}

Former School of Medicine, Hokkaido University

\section{Kiriko Nohara}

Former Scool of Medicine, Hokkaido University

\section{Tadashi Sagawa}

Faculty of Health Sciences, Hokkaido University

\section{Research article}

Keywords: HPV, cervical cancer, self-sampling, awareness, young women

Posted Date: October 1st, 2019

DOI: https://doi.org/10.21203/rs.2.15385/v1

License: (a) (i) This work is licensed under a Creative Commons Attribution 4.0 International License. Read Full License 


\section{Abstract}

Background

The rate of young Japanese women attending Cervical Cancer screenings is still low. There is a lack of studies that discussed awareness, preference, and anxiety of women to HPV self-sampling. The aim was to clarify the awareness of young women who want and do not want HPV self-sampling toward improvement the rate of attending Cervical Cancer screenings.

\section{Methods}

We carried out the observation study by self-administered questionnaires about the awareness of HPV selfsampling with the trial in a city, in Hokkaido, Japan. The subjects were selected at random to 25-29 years old women (837 persons) residing in a city. We compared their awareness between want and do not want selfsampling. For data analysis, statistical analysis software SPSS for Windows Ver.21 was used setting the significance level at below $5 \%$.

Results

Young women in this study who firstly responded wanting practice of self-sampling were $9.8 \%$, and not wanting in were $90.2 \%$. The reasons of young women that want self-sampling were "Free self-sampling supported from the city", "I can do it in my own time", and "I have experience of sexual intercourse". In contrast, the reasons of do not want self-sampling were "I have no symptom", and "I am anxious about doing the test by myself". The awareness of HPV self-sampling was low with all subjects, and they have few the general knowledge of Cervical Cancer.

Conclusion

There is a possibility to increase the number of young women who want self-sampling by using an HPV selfsampling trial of the opt-in method that also considers the emotions of the women. Young Japanese women who do not want self-sampling, tend to have a fear and anxiety toward self-sampling, in contrast, many of the women who conducted self-sampling prefer it. This study suggests the need of new practical education for self-sampling, including HPV infection, and Cervical Cancer prevention performed by clinicians, nurses and midwives.

\section{Background}

In 2018 worldwide, Cervical Cancer (CC) ranks third for both incidence and mortality[1], following breast, and lung cancer among women. Incidence of $\mathrm{CC}$ is the highest in Eastern-Africa regions. High mortality areas are in the Middle/Eastern/South/Western-Africa except for Northern-Africa, secondary areas are in SouthEastern/South-Central Asia, Micronesia and the Caribbean.

Recently, the incidence of and mortality ratefrom CC has increased yearly in Japanese women and it has markedly increased in the younger generation [2]. The incidence of CC excepted of carcinoma in-situ (CIS) in 25-29 year old Japanese women was 3.0 (per 100,000 people) in 2016 [3],and the mortality of the women 
was 0.3 (per 100,000 people) in 2017 [4]. However, the rate of people attending CC screenings, a preventive measure, was $42.4 \%$ in 25-69 year old and $26.5 \%$ in 20-29 year old Japanese women in 2016, being markedly lower than those in Western countries, and similar to middle income country rates [5].

Human papilloma virus (HPV) is generally known that HPV is transmitted by sexual intercourse and it is considered that CC is induced by continuous infection. There are more than 150 types of HPV and 15 types are carcinogenic, termed high-risk HPV. CC-preventive measures are the HPV vaccine and periodic screening. The effect of HPV vaccine to prevent HPV infections and cervical dysplasia has been confirmed [6], but the Ministry of Health, Labour and Welfare is temporarily withholding active recommendations of the HPV vaccination in Japan because of problematic media reports of adverse reactions, despite no medical evidence of the HPV vaccine causing the reported problems [7,8]. Accordingly, HPV vaccine coverage markedly declined to $0.3 \%$ [9] and periodic attending of CC screening has become an important CC-preventive method.

The Japan Society of Obstetrics and Gynecology (JSOG) adopted the Bethesda diagnostic criteria and revised the Japanese Guideline for Cervical Cancer Screening in 2009, instead of the diagnostic criteria based on the original JSOG classification of diagnosis [10].Conventional population-based screening of cervical and endometrial cancer of uterine body screening was mainly of cytology alone. Clinician-collected samplings, and calculated CC screening rates of ages specified were in 5 years intervals. Recently, the modified guideline for planning a domestic consensus has recommended CC screening of the target age 20 to 69 years and been added to HIV testing anew. In this modified guideline, two combination methods are clinician-collected sampling combined with HPV testing and self-sampling combined with HPV testing. If the appropriate follow up is not performed, it has a probability of lower effect than conventional cytology alone. Accordingly, new studies are recommended for dissemination and implementation, also a revised program of the CC screening results. However, the rate of Japanese women attending CC screening is low at present, and the reasons that have been given include, 'no time', 'bothersome', 'expensive', and 'embarrassed'[11], in spite of the issue of low $\mathrm{CC}$ screening rates due to a shortage of obstetrics and gynecologist [12].

Nobbenhuis et al. [13] have mentioned that self-sampling for HPV DNA testing seems suitable as an alternative screening tool for unscreened women. Recently, it has been shown that the diagnosis accuracy of HPV self-sampling (self-sampling) is equal to clinician-collected sampling [14-16]. Furthermore, there was no social harm or adverse events recorded in previous studies. However, there is a lack of studies that discussed awareness, preference, recognition/perception, and anxiety of women to self-sampling [17-21]. In a previous study of a community-based Canadian women, there was not a significant difference of preference between a Pap smear test performed by clinician or self-sampling, although they indicated a preference of self-sampling, due to comfort and personal feelings [22].There is no other study on the reasons of young women wanting or not wanting to perform self-sampling. In a trial performed in a rural city in Hokkaido, Japan, $90.1 \%$ of subjects did not want to do self-sampling [23], but the reason for it was not clarified. We suppose that young Japanese women were insufficiently aware of self-sampling or have lower preference rates for self-sampling at the present. Therefore, it is required to verify women's perspective toward optimal HPV self-sampling trials to increase the screening rate by resolving these reasons for not attending the screening and subsequently prevent CC. 
The objective of this study is to clarify the awareness of young women who want and do not want selfsampling, and discuss the issues for increasing the use of the test.

\section{Methods}

\section{Data sources}

The self-sampling trial project was conducted between July 1, 2018, and September 30, 2018, in rural a city in Hokkaido, Japan, and 2 questionnaire surveys were used as a quantitative study, performed employing postal mail using the opt-in method. Hokkaido prefecture, the population of which was 5,539,539 in 2018 , is located in the northernmost part of Japan and is the second largest island in Japan, and a city, with the population less than 100,000 is located in the middle-south area of Hokkaido.

\section{Questionnaire}

On Survey 1, Questionnaire 1 was enclosed in the invitation for the self-sampling test sent to subject by a city, and on Survey 2, Questionnaire 2 was enclosed when the self-sampling kit (Home smear set plus ${ }^{\circledR}$ ) and explanatory leaflet of the kit were sent. The subjects of Survey 1 were selected at random to 25-29 years old women residing in a city. Of the subjects of Survey 1 , those who wanted the self-sampling kit were the subject of Survey 2. Original questions were prepared referring to preceding studies [24,25]. In Questionnaire 1, age, occupation, final academic background, familial medical history of cancer, presence or absence of smoking and taking a lecture on $\mathrm{CC}$, histories of HPV vaccination, undergoing $\mathrm{CC}$ screening, the use of tampon and low-dose pill, experiences of sexual intercourse, pregnancy, delivery, and marital status were asked as attributes of the subjects. In addition, the reason for want and do not want self-sampling and knowledge concerning $\mathrm{CC}$ were surveyed. Knowledge concerning $\mathrm{CC}$ was divided into the following 4 fields and asked: [HPV self-sampling test; self-sampling exist, fact of same diagnosis accuracy levels between self-sampling and clinician-collected, required time of self-sampling, ordinary price, and important points of self-sampling], [CC and HPV; incidents age, symptom of cervical cancer, infection route, and maintain of HPV], [CC prevention method; 2 types of vaccine and $\mathrm{CC}$, benefits of $\mathrm{CC}$, required period of $\mathrm{CC}$, and low risks using condom during sexual intercourse], and [adverse reactions of HPV vaccine; symptom after vaccination, problematic media reports, and statement of Ministry of Health, Labor and Welfare]. Each field was comprised of 5 items and each item was scored 1. In Questionnaire 2, in addition to the attributes of the subjects asked in Questionnaire 1, impression of the use of the self-sampling test kit was surveyed. Multiple answers were asked regarding the reason for want or not want self-sampling, and the reason for carrying out self-sampling. This study adopted the opt-in method both survey 1 and 2. Specifically, we considered no attendant decision which not returned questionnaire and self-sampling kits. And it was classified to the category of not want self-sampling.

\section{Statistical analysis}


For data analysis, statistical analysis software SPSS for Windows Ver.21 was used setting the significance level at below $5 \%$, and the p-value with two-sided. On Survey 1 , the Mann-Whitney U-test, $\chi^{2}$ test, and Fischer's exact test were used for comparison of the attributes between women who wanted and did not want selfsampling, the reasons for wanting and not wanting self-sampling were summarized using descriptive statistics, and the Kruskal-Wallis test was used for comparison of the scores of the 4 fields of knowledge concerning CC. On Survey 2, the attributes of the subjects and impression of the use of the self-sampling kit were summarized using descriptive statistics.

\section{Results}

\section{Survey 1}

Young women who firstly responded wanting practice of self-sampling were $9.8 \%$ (82/837), and not wanting in were $90.2 \%$ (755/837) in survey 1 . The rate of response to Questionnaire 1 was $14.1 \%$ (118 responded). Excluding responses containing unclear answers, the valid response rate was $85.6 \%(101 / 118)$. Sixty-one and 40 subjects want and do not want the self-sampling test, respectively (Fig. 1).

As shown in Table 1, when the attributes of the subjects in survey 1 were compared between the young women who want $(n=61)$ and do not want $(n=40)$ self-sampling, a significant difference were noted in 3 items. The rates of young women who answered that "a familiar person has a cancer", "I have never attended CC screening", and "I have experience of sexual intercourse" were significantly higher in the young women who want self-sampling $(p<0.001, p=0.03, p=0.02)$. Figures 2 and 3 indicate the reasons for wanting and not wanting self-sampling, respectively. In the young women who wanting self-sampling, the main reasons selected were "Free self-sampling supported from the city (96.7\%)", "I can do it in my own time (96.7\%)", and "I have experience of sexual intercourse (85.2\%)". In the young women who do not wanting self-sampling, "I have undergone CC screening (60.0\%)", "I have no symptom (57.5\%)", and "I am anxious about doing the test by myself (45.0\%)" were mainly selected. Table 2 shows the results of comparison of the score of CC-related knowledge in all subjects $(n=101)$. The mean score of the 4 fields in all subjects is below half of the full score of 5. On comparison of the score among the 4 fields, the score of the field concerning [HPV selfsampling test] was significantly lower than those of the other three areas ([CC and HPV], [CC prevention method], and [adverse reactions of HPV vaccine]). On comparison between [CC prevention method] and [adverse reactions of HPV vaccine], the score of the former was significantly higher.

\section{Survey 2}

The Questionnaire in survey 2 response rate was 55.6\% (45 responded) and the valid response rate was $86.7 \%$ (39/45). Finally, respondents who conducted of self-sampling $86.7 \%$ (39/50) were effective respondents in survey 2 (Fig. 4). The impressions of the use of the self-sampling kit are shown in Table 3. Thirty-four (87.2\%), 36 (92.3\%), 32 (82.1\%), 36 (92.3\%), and 37 subjects (94.9\%) answered that "I could do it easily", "It took only a short time", "It was not painful", "It was not embarrassing", and "It was comfortable", respectively. Thirty-eight subjects (97.4\%) answered that the explanatory leaflet of self-sampling was easy to understand, the test by self-sampling was easier than undergoing CC screening with sampling by a clinician, 
and they would consider undergoing the self-sampling again. Of 24 subjects who had experiences of the use a tampon used during menstruation, $9(37.5 \%)$ and $10(41.7 \%)$ answered that self-sampling is "less painful" and "the same" compared with pain of tampon, respectively, and 9 (37.5\%) and 10 (41.7\%) answered that insertion was "easier" and "the same" compared with that of tampon, respectively (Table 4).

\section{Discussion}

Our sample size of subjects is low, similar to the study Nobbenhuis et al. [13]carried out, as the first study of HPV self-sampling. As found in their study, the use of the self-sampling devices is difficult ( $12 \%$ of subjects: 7 people out of 56 women), and $23 \%(13 / 56)$ of the women prefer the Pap smear test to the self-sampling because of the reasons "no problem with gynaecological examination" and "the self-sampling device is not practical". In brief, their result indicates that $77 \%$ of the participating women chose self-sampling by vaginal lavage above the Pap smear as an alternative screening tool.

According to the other previous study [23], the number women who want self-sampling is $9.9 \%$, and their result supported our survey. 1 result that 9.8\% (82/837) of young women answered to want self-sampling. Their study is similar to ours except a different unclear point, about the reason of not want self-sampling. Hanley et al. [23] mention that the opt-in method which confirmed the intention of wanting or not wanting to send self-sampling kits caused a low return ratio than with the direct-mailed/opt-out method. Tranberg et al. [26] mention also that there were much more women conducting self-sampling in the direct-mailed/opt-out method than women that used the opt-in method (direct: 9.4\%, opt-in: 8.3\%). Therefore, our result has a higher value in this comparative study. Our study verified the opt-in method as a trial of mailing self-sampling kits, and we got an effective return ratio. Accordingly, we think that the original questionnaire used in this study caused a slight increase in the motivation of applicants. Consequently, we can consider that there is a possibility of increasing the number of applicants who want self-sampling trial by using the opt-in method.

In addition, the following results are: "I can do it in my own time", "I can do it by myself", "I is not embarrassing", and "I think that self-sampling has less pain" (Fig. 3). These are respectively much higher than the survey conducted in the Netherlands by Bosgraaf et al. [24], and it speculates that self-sampling is easy to use and a good tool to solve the problem of non-attendance of CC screening also in Japan.

On the other hand, two items not seen in previous studies [24], "I have not received HPV vaccine" and "I have never received CC screening", make up more than half of the answers in this research. From 2013 to the present, in Japan, the Ministry of Health, Labor and Welfare has been temporarily withholding the active recommendation for HPV vaccine on account of excessive media reports of adverse reactions,which lowered the HPV vaccination coverage rate. Because young Japanese women are reluctant to be vaccinated with concerns about adverse reactions of the HPV vaccine and they do not undergo CC screening in gynecology departments due to the reasons mentioned above, and the two items above might be chosen more. Consequently, the self-sampling is an easy-to-use preventive method for young Japanese women who are in this situation. Moreovere, it is consider to be a breakthrough tool to improve the rate of women attending CC screenings. 
Our study verify that there are several issues with self-sampling, so the majority of the subjects selected are for the reasons of not wanting self-sampling, "I have undergone CC screening", "I have no symptom", and "I am anxious about doing the test by myself". These results imply that many women consider that the test is no longer necessary if they previously underwent the screening. Many women do not know the fact that CC is asymptomatic in its early stages, so having a suspicion and using the technique of self-sampling is good.

In a study performed by Nelson et al. [27], "the result may not be accurate because the sample is collected by myself" and "I am anxious about doing the test by myself" are selected. These 2 items are also selected as the reasons for not wanting self-sampling, but the rate was $45.0 \%$, being higher than that in the study reported by Nelson et al. [27], clarifying that young Japanese women not wanting self-sampling had a stronger fear of self-sampling and anxiety about the accuracy compared with women in other countries, in our study.

On the other hand, receptivity by women who actually performed self-sampling is high in other countries [26], and about $90 \%$ of women who perform self-sampling also have a positive impression of the use of the selfsampling kits in our study. In addition, it is clarified that $97.4 \%$ of the subjects prefer self-sampling to sampling by a clinician and this is higher than $(62.0 \%)$ in a survey performed by Winer et al. [19],clarifying that young Japanese women strongly prefer self-sampling compared with women in other countries.

Regarding the impression of the use of the self-sampling kit compared with that of a tampon used during menstruation, it is suggested that the kit is more comfortable than or comparable to a tampon. These impressions by women who actually used the self-sampling kit may serve as peer-support and material to decide on doing or not doing self-sampling for women who have never carried it out.

This time, comparing the knowledge score of [HPV self-sampling test], [CC and HPV], [CC prevention method], [adverse reactions of HPV vaccine] in our original questionnaire, and the score of [HPV self-sampling test] was significantly lower than those of the other three areas ([CC and HPV], [CC prevention method], and [adverse reactions of HPV vaccine]). We consider that the sex education in Japan is one factor connected to this. The awareness of young women with an idea thinking it is unnecessary to undergone CC screening because of no symptoms, as one of the reasons for not wanting self-sampling, has to be modified to the right recognition in sex education since early childhood. Because even if there are no symptoms, women engaged in sexual intercourse are required to undergo ordinary CC screening or self-sampling to prevent HPV infections unless they get vaccinations. From these view points, we regard that the background factor that the selfsampling is not sufficient popular, is in the fact that insufficient of correct knowledge to prevent HPV infection and the incidence of CC. To promote the right knowledge of HPV self-sampling and prevention of CC is a necessary condition due to safety and the efficacy of the self-sampling kit for young women.

Williams et al. [28] report that the lack of knowledge related to HPV and self-sampling is a barrier to wanting the test, and Crofts et al. [29] and Penaranda et al. [30] argue that the number of women who prefer selfsampling increased by educational interventions on CC and self-sampling. Moreover, it is eminently important to explain about self-sampling safely, efficacy, how to use kits, the diagnosis accuracy, and follow up system according to women's life events, with face to face instructing by clinicians, nurses and midwives as well as training from instruction booklets, DVDs, and explanatory leaflets with self-sampling kit for sustainable selfsampling. Consequently, in this study, it is clear to see there is a lack of the right knowledge in regards to the 
background of self-sampling dissemination. In the future, as the enhanced awareness of young women's selfmanagement, it is urgently to give an opportunity so they can select alternatives with confidence, either for CC screenings or self-sampling by themselves.

In this study, there is a limitation that the number of eligible subjects is restricted to the population and area of a city and it differs from the pilot study nationwide. We could not get enough subjects without donations for the self-sampling kits. In the Netherlands and Australia, providing self-sampling to women who have never attended the screening is incorporated into the national CC screening program. $[31,32]$ In addition, Duke et al. [33] reported that the CC screening-attending rate was increased from 15.2 to $67.4 \%$ by providing selfsampling in Newfoundland, Canada. Introduction of self-sampling to women who had never undergone CC screening may lead to an increase in the screening-attending rate in Japan, as achieved in these countries.

This study suggests in focus on dissemination and implementation of new practical education. To rapidly increase self-sampling in Japan, it is necessary to review sex education of the younger generation, increase correct knowledge concerning $\mathrm{CC}$ to mothers, and provide information on self-sampling using media rooted in daily life. The latest review mentions that no studies offered comparative data for frequency of CC screening, nor for social harm and adverse events, [34] although, the scope in our study considered the emotions of young women in their vulnerable years. Our research result is to confirm the reasons why people do not return the questionnaire and self-sampling kit. Our findings on the awareness of young women who want to do and not want to do self-sampling is useful to a program as feasible, to give support to ensure reproductive health and the rights of young women in the future.

\section{Conclusion}

There is a possibility to increase the number of young women who want self-sampling by using an HPV selfsampling trial of the opt-in method that also considers the emotions of the women. In this study, young women, who do not want self-sampling, tend to have a fear and anxiety toward self-sampling. Although, many of the young women who conducted self-sampling prefer it. In addition, almost all subjects have a lack of general knowledge on $\mathrm{CC}$, and awareness of self-sampling is still low. Consequently, we suggest the need of new practical education for self-sampling, including HPV infection, and CC prevention performed by clinicians, nurses and midwives.

\section{Abbreviations}

CC: Cervical Cancer, CIS: carcinoma in-situ, HPV: Human papilloma virus, JSOG: Japan Society of Obstetrics and Gynecology,

\section{Declarations}

\section{Ethics approval and consent to participants}

This study was approved by the Ethical Review Board of the Graduate School of Health Sciences, Hokkaido University (approval number: 17-114-1, approved: March 29, 2018), and the trial was registered in a city, in 
Hokkaido, Japan (approved: May 23, 2018). We confirmed to informed consent by written to all participants in this study; that can reject of participate when it does not want the self-sampling and no answer the questionnaire, and collected information kept confidencial.

\section{Consent for publication}

Not applicable.

\section{Availability of data and material}

Our analyed data in this study is a part of a shared of Cervical Cancer screening as population-based in a city, in Hokkaido, Japan, and the self-sampling kits were sent to applicants of a city. Therefor, our data in not available for ethical reasons.

\section{Competing interests}

There are no competing interests.

\section{Funding}

No funding was received to support this study.

\section{Author Contributions}

ST led the study design, collected data, did data coding and analysis, and drafted the manuscript. YI contributed to the study design, collecting data, and revising the manuscript. NN, KN and KNo reviewed it. TS contributed to the study design, interpretation of results and drafted manuscripts. All authors read and approved the final manuscript.

\section{Acknowledgments}

Special thanks to participants for permission to share information and work together on our study.

\section{Reference}

1.Ferlay J, Colombet M, Soerjomataram I, Mathers C, Parkin DM, Piñeros M, et al. Estimating the global cancer incidence and mortality in 2018: GLOBOCAN sources and methods. Int J Cancer. 2019;144(8):1941-53. http://doi: 10.1002/ijc.31937. 
2.Guideline based on the effective evaluation of cervical cancer. Japan Council for Quality Health Care. 2009. Accessed 17 June 2019. https://minds.jcqhc.or.jp/n/med/4/med0071/G0000193/0005 (in Japanese)

3.Japanese Ministry of Health, Labour and Welfare『lncidence of Cancer in Japan. MHLW. 2016. Accessed 17 June 2019. https://www.mhlw.go.jp/content/10900000/000468976.pdf (in Japanese)

4.National Cancer Center Japan. CANCER STATISTICS IN JAPAN '16. Accessed 17 June 2019. https://ganjoho.jp/reg_stat/statistics/index.html

5.Organisation for Economic Co-operation and Development (OECD). OECD Health Statistics 2018. Accessed 29 Sep 2018. https://stats.oecd.org/index.aspx? DataSetCode = HEALTH_STAT

6.Centers for Disease Control and Prevention, Epidemiology and Prevention of Vaccine-Preventable Diseases. Chapter 11: Human Papillomavirus. Accessed 16 June 2019.

https://www.cdc.gov/vaccines/pubs/pinkbook/hpv.html

7.Suzuki S, and Hosono A. No association between HPV vaccine and reported post-vaccination symptoms in Japanese young women: results of the Nagoya study. Papillomavirus Res. 2018;5:93-103. http://doi:

10.1016/j.pvr.2018.02.002.

8.Miyagi E, Motoki Y, Asai-Sato M, Taguri M, Morita S, Hirahara F, et al. Web-based recruiting for a survey on knowledge and awareness of cervical cancer prevention among young women living in Kanagawa prefecture, Japan. Int. J Gynecol Cancer. 2014;24(7):1347-55. http://doi: 10.1097/IGC.0000000000000220.

9.Japanese Ministry of Health, Labour and Welfare囚Number of regular vaccination practitioners. MHLW. 2018. Accessed 17 June 2019. https://www.mhlw.go.jp/topics/bcg/other/5.html (in Japanese)

10.Hamashima C, Aoki D, Miyagi E, Saito E, Nakayama T, Sagawa M, et al. The Japanese Guideline for Cervical Cancer Screening. Jpn J Clin Oncol. 2010;40(6):485-502. http://doi: 10.1093/jjco/hyq036.

11.Matsuo I, Nishizawa Y, Matsuo K, Kagiya A. Cervical cancer screening behavior and factors associated with screening behavior. Hirosaki med. J. 2014;64 (2):103-118.

12. Sano H, Goto R, Hamashima C. Does lack of resources impair access to breast and cervical cancer screening in Japan? PLoS One. 2017;13;12(7):e0180819. http://doi: 10.1371/journal.pone.

0180819.

13. Nobbenhuis MA, Helmerhorst TJ, van den Brule AJ, Rozendaal L, Jaspars LH, Voorhorst FJ, et al. Primary screening for high risk HPV by home obtained cervicovaginal lavage is an alternative screening tool for unscreening women. J Clin Pathol. 2002;55(6):435-9.

14.Arbyn M, Verdoodt F, Snijders PJ, Verhoef VM, Suonio E, Dillner L, et al. Accuracy of human pap illomavirus testing on self-collected versus clinician-collected samples: A meta-analysis. Lancet Oncol. 2014;15(2):17283. http://doi: 10.1016/S1470-2045(13)70570-9. 
15.Ketelaars PJW, Bosgraaf RP, Siebers AG, Massuger LFAG, van der Linden JC, Wauters CAP, et al. High-risk human papillomavirus detection in self-sampling compared to physician-

taken smear in a responder population of the Dutch cervical screening: Results of the VERA study. Prev Med. 2017;101:96-101. http://doi: 10.1016/j.ypmed.2017.05.021.

16.Polman NJ, Ebisch RMF, Heideman DAM, Melchers WJG, Bekkers RLM, Molijn AC, et al. Performance of human papillomavirus testing on self-collected versus clinician-collected samples for the detection of cervical intraepithelial neoplasia of grade 2 or worse: a randomised, paired screen-positive, non-inferiority trial. Lancet Oncol. 2019;20(2):229-238. http://doi: 10.1016/S1470-2045(18) 30763-0.

17.Oshima S, and Maezawa M. Perception of cervical screening among Japanese university students who have never had a Pap smear: a qualitative study. Asian Pac J Cancer Prev. 2013;14(7):4313-8.

http://dx.doi.org/10.7314/APJCP.2013.14.7.4313

18.Sultana F, Mullins R, English DR, Simpson JA, Drennan KT, Heley S, et al. Women's experience with homebased self-sampling for human papillomavirus testing. BMC Cancer. 2015;15:849. http://doi:

10.1186/s12885-015-1804-x

19.Winer RL, Gonzales AA, Noonan CJ, Cherne SL, Buchwald DS; Collaborative to Improve Native Cancer Outcomes (CINCO). Assessing Acceptability of Self-Sampling Kits, Prevalence, and Risk Factors for Human Papillomavirus Infection in American Indian Women. J Community Health. 2016;41(5):1049-61. http://doi: 10.1007/s10900-016-0189-3.

20.Hanley SJ, Fujita H, Yokoyama S, Kunisawa S, Tamakoshi A, Dong P, et al. HPV self-sampling in Japanese women: A feasibility study in population with limited experience of tampon use. J Med Screen. 2016;23(3):164-70. http://doi 10.1177/096914135625702.

21.Thay S, Goldstein A, Goldstein LS, Govind V, Lim K, Seang C. Prospective cohort study examining cervical cancer screening methods in HIV-positive and HIV-negative Cambodian Women: a comparison of human papilloma virus testing, visualization with acetic acid and digital colposcopy. BMJ Open. 2019;9(2):e026887. http://doi:10.1136/bmjopen-2018-026887

22.Zehbe I, Jackson R, Wood B, Weaver B, Escott N, Severini A, et al. Community-randomised controlled trial embedded in the Anishinaabek Cervical Cancer Screening Study: human papillomavirus self-sampling versus Papanicolaou cytology. BMJ Open. 2016;6(10):

e011754. http://doi: 10.1136/bmjopen- 2016- 011754.

23. Hanley S, Fujita H, Tamakoshi A, et alهHPV self sampling: A novel method to increase cervical screening uptake囚Japanese association for cancer detection and diagnosis. 2014;28(1):22. unpublished.

24.Bosgraaf RP, Ketelaars PJ, Verhoef VM, Massuger LF, Meijer CJ, Melchers WJ, et al. Reasons for nonattendance to cervical screening and preferences for HPV self-sampling in Dutch women. Prev Med. 2014;64:108-13. http://doi: 10.1016/j.ypmed.2014.04.011. 
25.Madzima TR, Vahabi M, Lofters A. Emerging role of HPV self-sampling in cervical cancer screening for hard-to-reach women Focused literature review. Can Fam Physician. 2017;63(8):597-601.

26.Tranberg M, Bech BH, Blaakær J, Jensen JS, Svanholm H, Andersen B. HPV self-sampling in cervical cancer screening: the effect of different invitation strategies in various socioeconomic groups - a randomized controlled trial. Clin Epidemiol. 2018;10:1027-1036. http://doi: 10.2147/CLEP.S164826.

27.Nelson EJ, Maynard BR, Loux T, Fatla J, Gordon R, Arnold LD. The acceptability of self-sampled screening for HPV DNA: a systematic review and meta-analysis. Sex Transm Infect. 2017;93(1):56-61. http://doi: 10.1136/sextrans-2016-052609.

28. Williams D, Davies M, Fiander A, Farewell D, Hillier S, Brain K. Women's perspectives on human papillomavirus self-sampling in the context of the UK cervical screening programme. Health Expect. 2017;20(5):1031-40. http://doi: 10.1111/hex.12544.

29.Crofts V, Flahault E, Tebeu PM, Untiet S, Fosso GK, Boulvain M, et al. Education efforts may contribute to wider acceptance of human papillomavirus self-sampling. Int J Womens Health. 2015;7:149-54. http://doi: 10.2147/IJWH.S56307.

30.Penaranda E, Molokwu J, Flores S, Byrd T, Brown L, Shokar N. Women's attitudes toward cervicovaginal self-sampling for high-risk HPV infection on the US-Mexico border. J Low Genit Tract Dis. 2015;19(4):323-8. http://doi: 10.1097/LGT.0000000000000134.

31.National Institute for Public Health and the Environment Ministry of Health, Welfare and Sport. Screening for CERVICAL CANCER Invitation RIVM, 2018. Accessed 5 Dec 2018. https://www.rivm.nl/sites/default/files/201811/96987_009285_Uitnodigingsfolder_BVO_BMHK_ENG_TG.pdf.

32.Australian Government Department of Health. National cervical screening program. Australian Government, 2018. Accessed 17 June 2019.

https://www.cancerscreening.gov.au/internet/screening/publishing.nsf/Content/cervical-screening-1

33.Duke P, Godwin M, Ratnam S, Dawson L, Fontaine D, Lear A, et al. Effect of vaginal self-sampling on cervical cancer screening rates: a community-based study in Newfoundland. BMC Women's Health. 2015;15:47. http://doi: 10.1186/s12905-015-0206-1.

34.Yeh PT, Kennedy CE, de Vuyst H, Narasimhan M. Self-sampling for human papillomavirus (HPV) testing: a systematic review and meta-analysis. BMJ Glob Health. 2019;4(3):e001351. http://doi: 10.1136/bmjgh2018-001351.

\section{Tables}


Table 1. Comparison of characteristics in survey1

\begin{tabular}{|c|c|c|c|}
\hline & $\begin{array}{c}\text { Want } \\
(\mathrm{n}=61)\end{array}$ & $\begin{array}{c}\text { Not want } \\
(\mathrm{n}=40)\end{array}$ & p-Value \\
\hline Age (mean \pm SD) & $26.95 \pm 1.33$ & $26.98 \pm 1.07$ & $0.88^{\dagger}$ \\
\hline \multicolumn{4}{|l|}{ Occupation } \\
\hline Medical workers & 9 & 6 & $1.00^{\ddagger}$ \\
\hline Non-medical workers & 52 & 34 & \\
\hline \multicolumn{4}{|l|}{ Final academic background } \\
\hline High school & 15 & 12 & $0.56^{\ddagger}$ \\
\hline Vocational school or junior college & 28 & 14 & \\
\hline University & 18 & 14 & \\
\hline \multicolumn{4}{|l|}{ Familial medical history of cancer } \\
\hline Yes & 40 & 9 & $<0.001^{\ddagger}$ \\
\hline No & 21 & 31 & \\
\hline \multicolumn{4}{|l|}{ Smoking } \\
\hline Yes & 11 & 5 & $0.64^{\ddagger}$ \\
\hline No & 50 & 35 & \\
\hline \multicolumn{4}{|c|}{ Have you taken lectures on Cervical Cancer? } \\
\hline Yes & 11 & 12 & $0.25^{\ddagger}$ \\
\hline No & 50 & 28 & \\
\hline \multicolumn{4}{|l|}{ Have you received HPV vaccination? } \\
\hline Yes & 1 & 3 & $0.30^{\S}$ \\
\hline No & 60 & 37 & \\
\hline \multicolumn{4}{|c|}{ Have you undergone Cervical Cancer screening? } \\
\hline Yes & 28 & 28 & $0.03^{\ddagger}$ \\
\hline No & 33 & 12 & \\
\hline \multicolumn{4}{|l|}{ Have you used a tampon? } \\
\hline Yes & 38 & 19 & $0.21^{\ddagger}$ \\
\hline No & 23 & 21 & \\
\hline \multicolumn{4}{|l|}{ Use of low dose pill } \\
\hline Yes & 5 & 6 & $0.34^{\S}$ \\
\hline No & 56 & 34 & \\
\hline \multicolumn{4}{|l|}{ Have you had sexual intercourse? } \\
\hline Yes & 61 & 36 & $0.02^{\S}$ \\
\hline No & 0 & 4 & \\
\hline \multicolumn{4}{|l|}{ Have you ever been pregnant? } \\
\hline Yes & 28 & 19 & $1.00^{\ddagger}$ \\
\hline No & 33 & 21 & \\
\hline \multicolumn{4}{|l|}{ Have you ever given birth? } \\
\hline Yes & 23 & 14 & $0.95^{\ddagger}$ \\
\hline No & 38 & 26 & \\
\hline \multicolumn{4}{|l|}{ Are you married? } \\
\hline Yes & $\begin{array}{l}34 \\
27\end{array}$ & $\begin{array}{l}27 \\
12\end{array}$ & $0.23^{\ddagger}$ \\
\hline
\end{tabular}

n=101, † Mann-Whitney U test. $\ddagger$ Pearson's $\chi^{\square-t e s t . ~} \S$ Fischer's exact test. SD: standard deviation, HPV: human papillomavirus.

\section{Figures}


Table 2. Comparison 4 areas of knowledge about Cervical Cancer

\begin{tabular}{|c|c|c|c|}
\hline & \multicolumn{2}{|c|}{ Score (full score: 5 points) } & \multirow[t]{2}{*}{$\mathrm{p}$-Value } \\
\hline & mean \pm SD & median & \\
\hline HPV self-sampling test & $0.19 \pm 0.82$ & 0.0 & \\
\hline - Cervical Cancer and HPV & & & $<0.001$ \\
\hline - Preventive methods against Cervical Cancer & & & $<0.001$ \\
\hline - Adverse reactions of HPV vaccine & & & $<0.001$ \\
\hline Cervical Cancer and HPV & $1.69 \pm 1.86$ & 1.0 & \\
\hline - Preventive methods against Cervical Cancer & & & $<0.001$ \\
\hline - Adverse reactions of HPV vaccine & & & 0.32 \\
\hline Cervical Cancer prevention method & $2.05 \pm 1.53$ & 2.0 & \\
\hline - Adverse reactions of HPV vaccine & & & 0.08 \\
\hline Adverse reactions of HPV vaccine & $1.28 \pm 1.77$ & 0.0 & \\
\hline
\end{tabular}

Table 3. The impressions of the use of the self-sampling kit

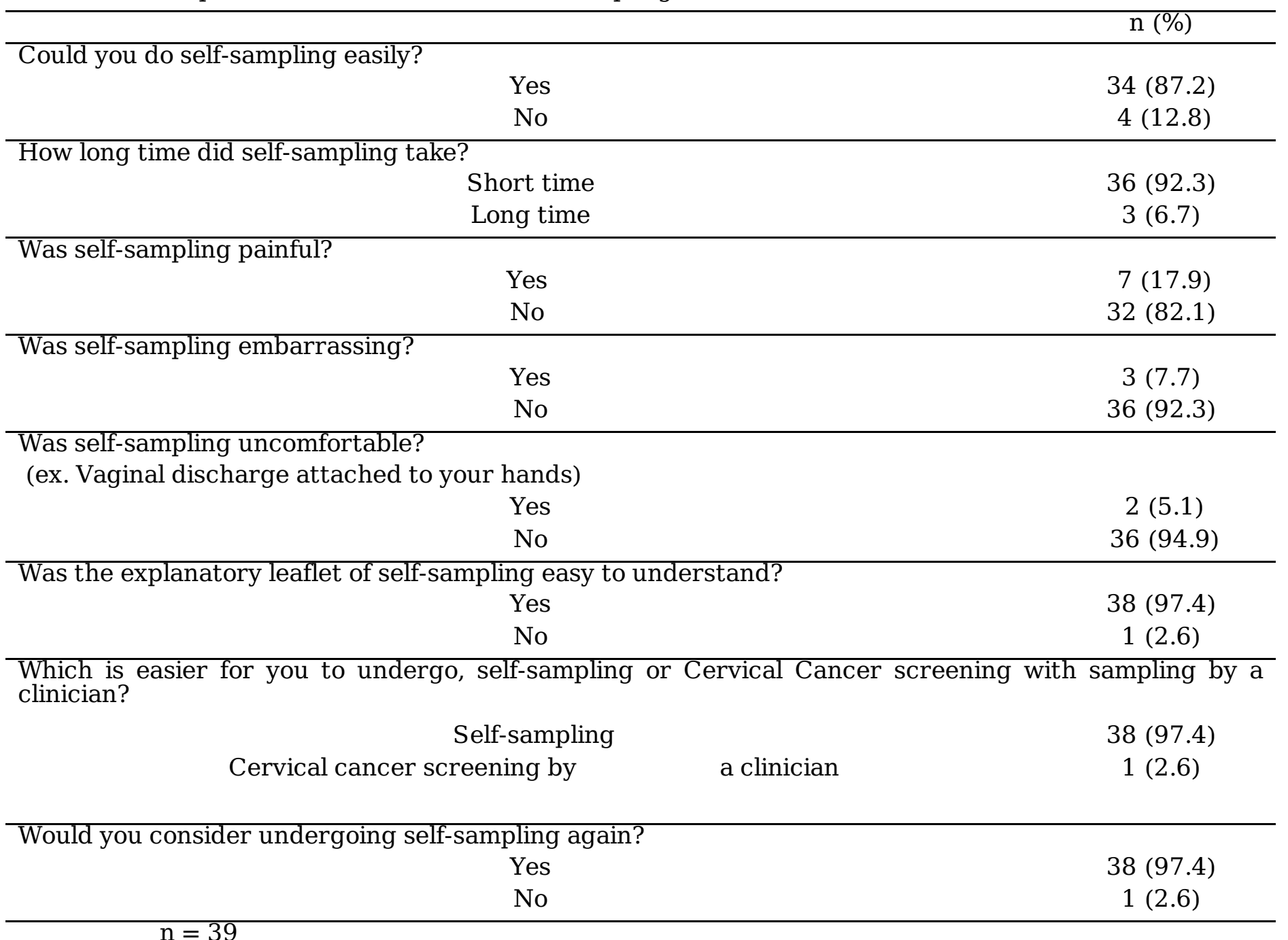


Table4. Feeling to use self-sampling compared with a tampon

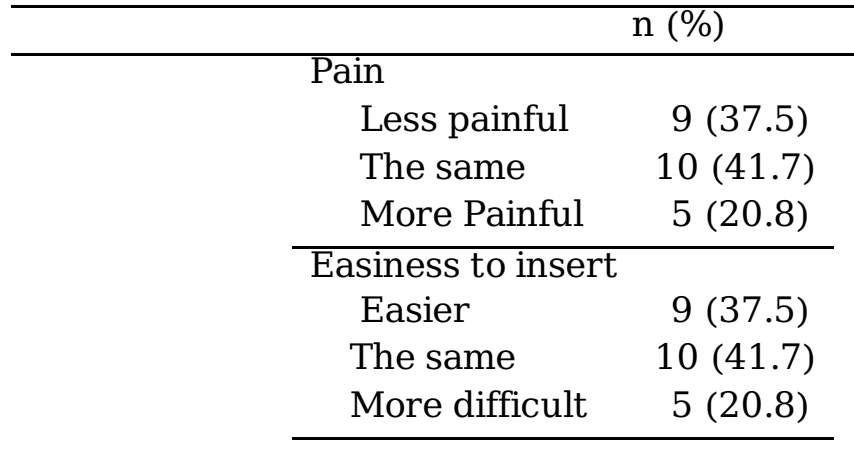

$\mathrm{n}=24$

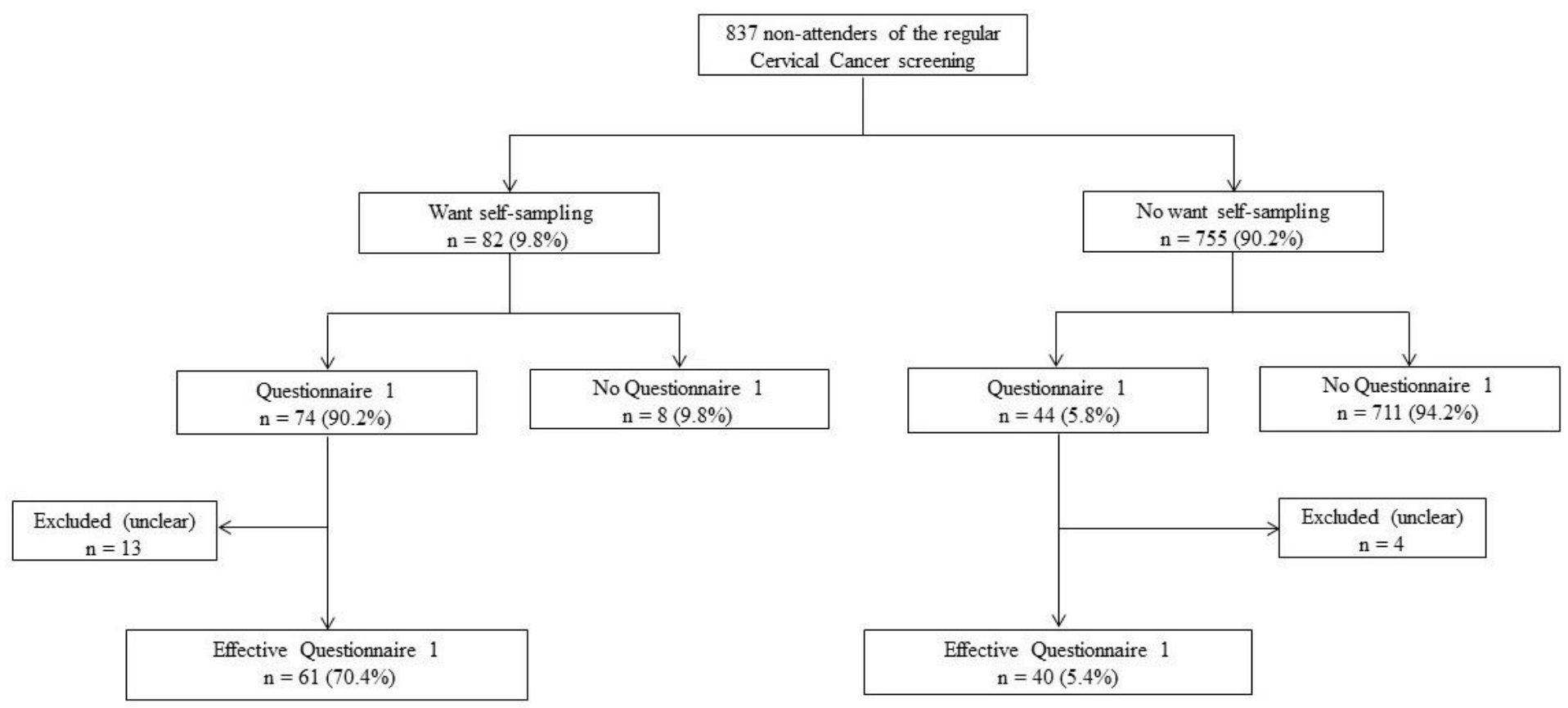

Figure 1

Flow chart of the study population in survey 1 
Free self-sampling supported from the city

I can do it in my own time

I have experience of sexual intercourse

I can do it by myself

I have never received HPV vaccine

Self-sampling is not embarrassing

I have never attended cervical cancer screening

Self-sampling may be less painful

Recommendations from parents or friends

I have anxious symptoms

0$$
0
$$

HPV: human papillomavirus.
Multiple answers, $\mathrm{n}=61$

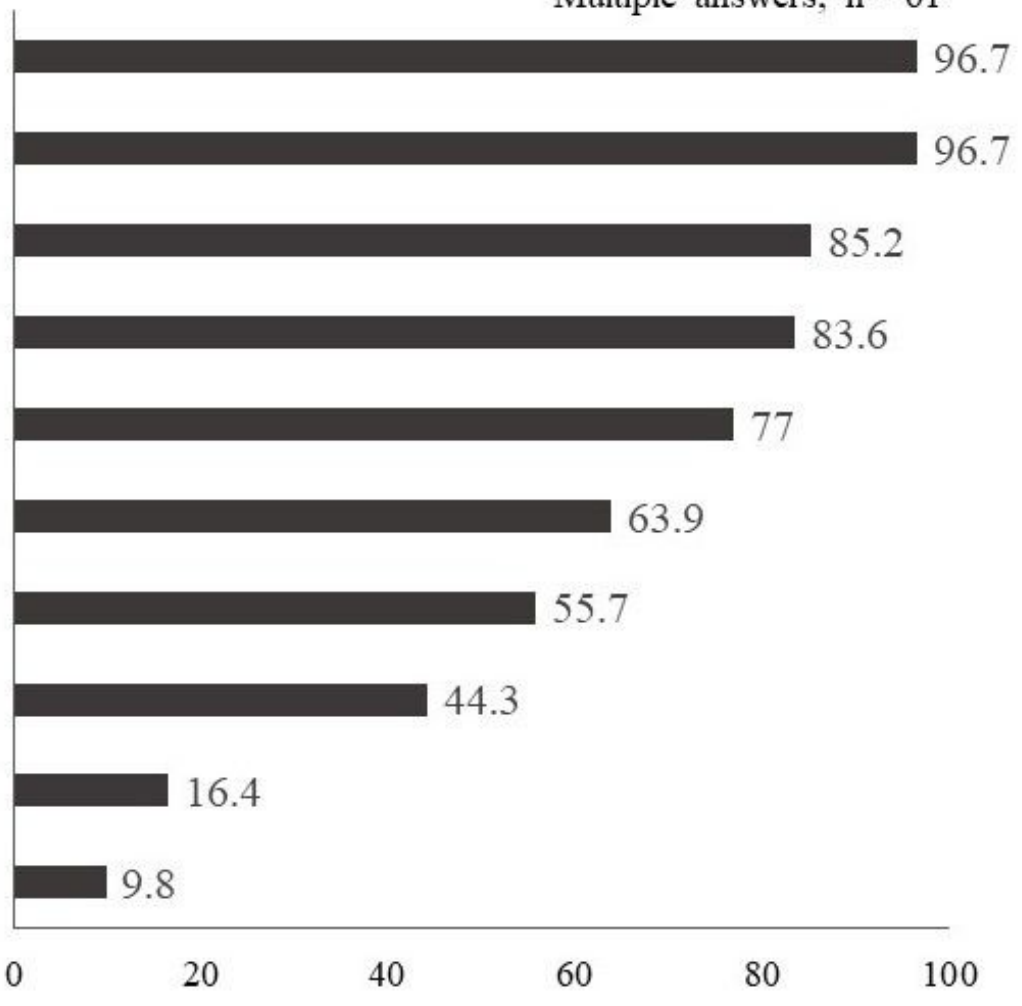

Percentage (\%)

\section{Figure 2}

The reasons for wanting self-sampling

Multiple answers, $n=40$

I have undergone cervical cancer screening

I have no symptom

I am anxious about doing the test by myself

The result may not be accurate because the sample is collected by myself

Bothersome

No time

I have no experience of sexual intercourse

I am afraid of the result for self-sampling

I have recieved HPV vaccine

I think I do not get cervical cancer

HPV: human papillomavirus.

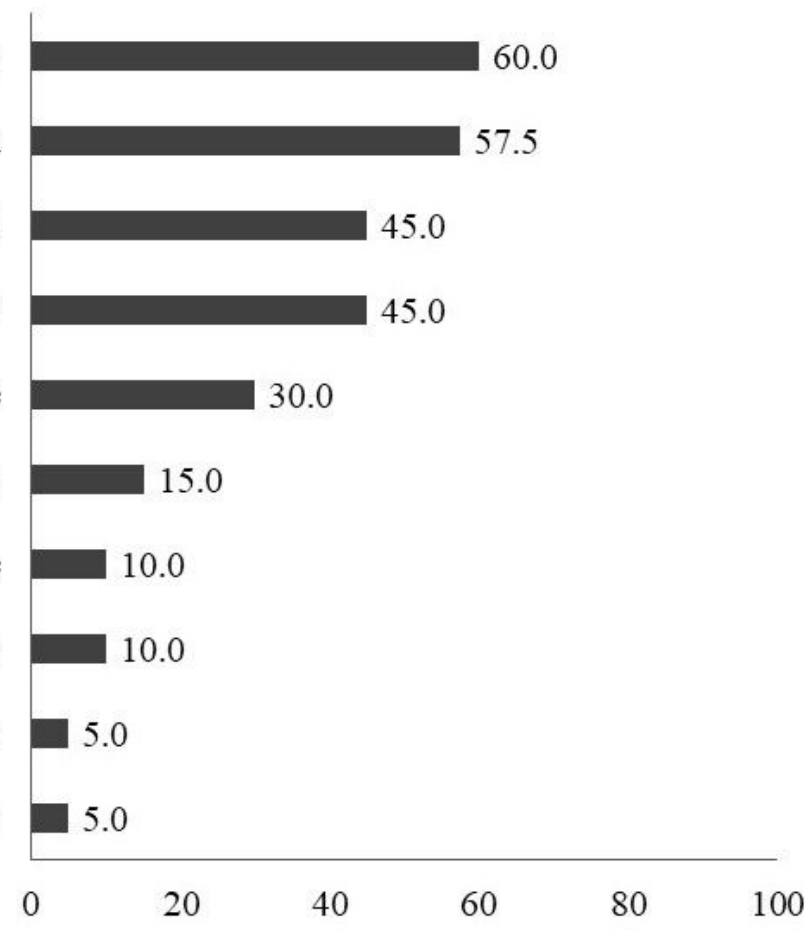

Percentage (\%) 
Figure 3

The reasons for not wanting self-sampling

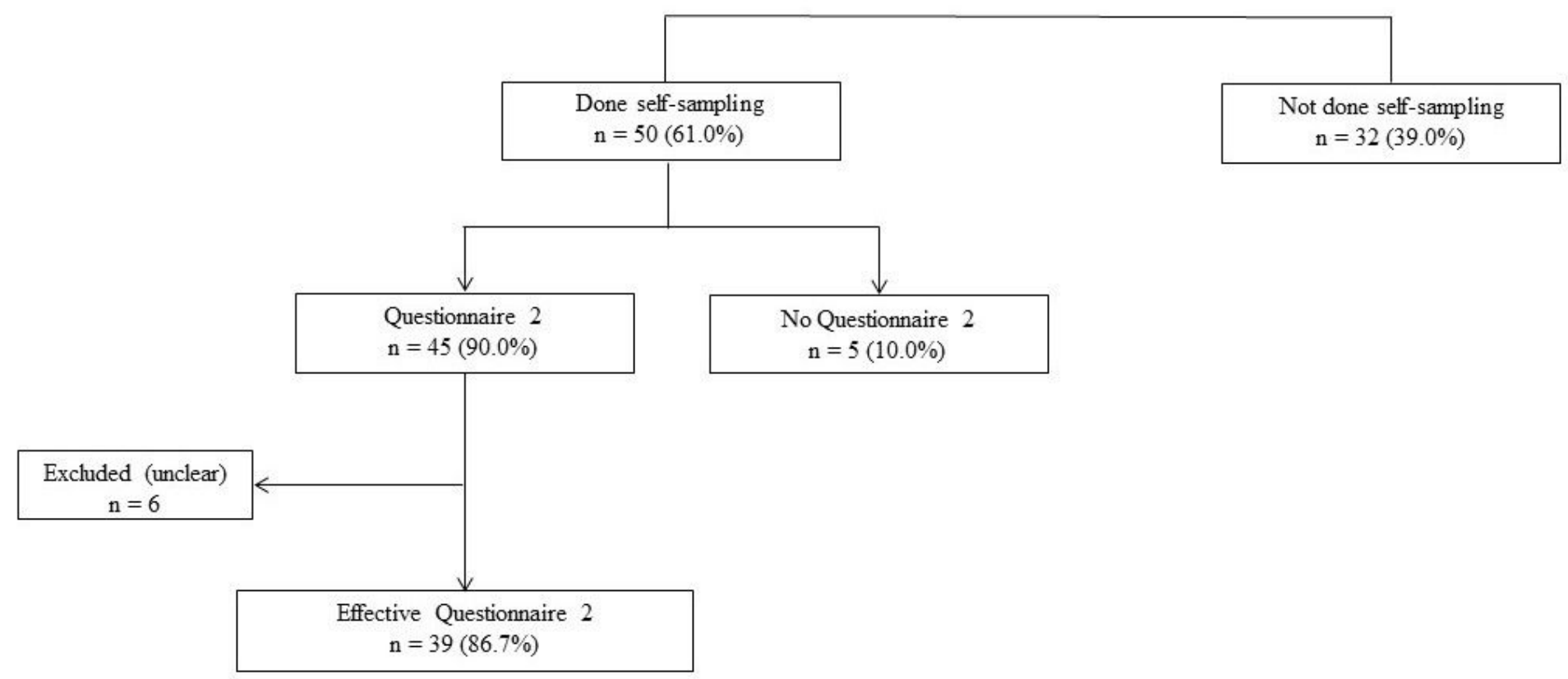

\section{Figure 4}

Flow chart of the study in survey 2 